\title{
Безызлучательный перенос энергии в гибридных наноструктурах с различной размерностью
}

\author{
(С) А.И. Хребтов ${ }^{1}$, Р.Р. Резник ${ }^{2}$, Е.В. Убыйвовк ${ }^{4}$, А.П. Литвин ${ }^{2}$, И.Д. Скурлов ${ }^{2}$, П.С. Парфёнов ${ }^{2}$, \\ А.С. Кулагина ${ }^{1,2}$, В.В. Данилов ${ }^{3}$, Г.Э. Цырлин ${ }^{1,2,5,6}$ \\ ${ }^{1}$ Санкт-Петербургский Академический университет - научно-образовательный центр нанотехнологий \\ Российской академии наук, \\ 194021 Санкт-Петербург, Россия \\ ${ }^{2}$ Санкт-Петербургский национальный исследовательский университет \\ информационных технологий, механики и оптики, \\ 197101 Санкт-Петербург, Россия \\ ${ }^{3}$ Петербургский государственный университет путей сообщения, \\ 191031 Санкт-Петербург, Россия \\ ${ }^{4}$ Институт физики им. В.А. Фока Санкт-Петербургского государственного университета, \\ 198504 Петродворец, Россия \\ ${ }^{5}$ Институт аналитического приборостроения Российской академии наук, \\ 190103 Санкт-Петербург, Россия \\ ${ }^{6}$ Санкт-Перебургский государственный электротехнический университет „ЛЭТИ“ им. В.И. Ульянова (Ленина), \\ 197376 Санкт-Петербург, Россия \\ E-mail: khrebtovart@mail.ru
}

Поступила в Редакцию 24 апреля 2019 г.

В окончательной редакции 29 апреля 2019 г.

Принята к публикации 29 апреля 2019 г.

\begin{abstract}
Впервые представлена композитная наноструктура на основе квазиодномерных нитевидных нанокристаллов InP с нановставкой InAsP, выращенных на подложке $\mathrm{Si}(111)$ методом молекулярно-пучковой эпитаксии, и нульмерных коллоидных квантовых точек CdSe/ZnS. Экспериментально подтверждено наличие безызлучательного переноса энергии между составляющими гибридной наноструктуры, а именно между коллоидными квантовыми точками и нановставкой.
\end{abstract}

Ключевые слова: молекулярно-пучковая эпитаксия, нитевидные нанокристаллы, коллоидные квантовые точки, безызлучательный перенос энергии.

DOI: 10.21883/FTP.2019.09.48141.25

\section{1. Введение}

В последнее время особое внимание уделяется созданию и исследованию гибридных наноструктур, состоящих из полупроводниковых нанокристаллов различной размерности. Так, в работах [1-3] продемонстрирована перспективность применения систем на основе квазиодномерных нитевидных нанокристаллов (ННК) и нульмерных коллоидных квантовых точек (КТ) в области фотовольтаики, фотодетекции и детекции газов. Недавно нами была показана возможность создания гибридной нанокомпозитной структуры на основе ансамбля GaAs ННК, выращенных методом молекулярно-пучковой эпитаксии (МПЭ) на подложках $\mathrm{GaAs}(111)$ и $\mathrm{Si}(111)$, с осажденными на них коллоидными квантовыми точками $\mathrm{CdSe} / \mathrm{ZnS}$ и $\mathrm{PbS}[4,5]$.

Одним из важных проявлений взаимодействия между составляющими частями гибридных наноструктур является безызлучательный перенос энергии (FRET), механизм которого впервые был теоретически описан Ферстером для молекулярных систем [6]. Правомерность применения теории FRET к полупроводниковым КТ (как коллоидным, так и эпитаксиальным) была про- демонстрирована на различных структурах, содержащих нанокристаллы [7-9,12]. В работе [10] разработан теоретический формализм для безызлучательного переноса энергии ферстерского типа для систем с комбинацией различных наноструктур (КТ, ННК, квантовая яма).

Исследование динамики распада возбужденных состояний в излучателях на основе гибридных наноструктур имеет ключевое значение для понимания многих физических и химических процессов, возникающих в процессе практического использования наноматериалов. Как известно, InAsP является одним из ключевых материалов для высокоскоростной электроники и для задач, связанных с ближним инфракрасным (ИК) излучением. В настоящей работе впервые приведены результаты спектральных и кинетических исследований ИК люминесценции новой композитной структуры, состоящей из HHK InP с нановставкой InAsP, выращенных на подложке $\mathrm{Si}(111)$ и нанесенных коллоидных КТ CdSe/ZnS.

\section{2. Эксперимент}

ННК были синтезированы методом МПЭ на установке Compact 21 (Riber). Технология роста ННК подроб- 
но описана в работе [11]. Использование специальной методики подготовки подложек непосредственно перед ростом позволило получить практически 100\% когерентных по отношению к подложке нитевидных нанокристаллов. Коллоидные КТ имели структуру типа ядро $(\mathrm{CdSe}$, диаметром около $3 \mathrm{Hм})$ - оболочка $(\mathrm{ZnS})$ и были покрыты лигандным слоем триоктилфосфиноксида. Раствор КТ в толуоле $\left(C \approx 10^{-6} \mathrm{M}\right)$ с помощью микропипетки наносился на подложку с ННК. Структурные свойства образцов исследовались с помощью сканирующего электронного микроскопа (СЭМ) Supra 25 и просвечивающего электронного микроскопа (ПЭМ) TITAN 80/300. Спектр ФЛ коллоидных КТ был записан с использованием CCD-камеры с кремниевой матрицей, а времена жизни фотолюминесценции КТ измерялись с помощью лазерного сканирующего люминесцентного микроскопа MicroTime 100 (PicoQuant).

В спектральных исследованиях массива ННК с нановставкой в качестве возбуждающих источников использовались непрерывно излучающие лазеры (с длинами волн 405, 532 и 633 нм), мощность излучения каждого составила $\sim 6$ мВт. Вторичное излучение собиралось по стандартной $90^{\circ}$ схеме, возбуждающее излучение отсекалось соответствующим светофильтром. Полученные спектры нормировались на чувствительность детектора. Спектры ФЛ в ближнем ИК-диапазоне были записаны с использованием InGaAs-фотодиода (Hamamatsu), в качестве спектрального прибора использовался дифракционный монохроматор (линейная дисперсия 6.5 нм). При исследовании кинетики ФЛ нановставки в качестве источника возбуждения использовался импульсный лазер с длиной волны 633 нм (частота следования $\sim 2.5$ МГц, энергия в импульсе $\sim 6$ нДж, длительность импульса $<100$ пс).

\section{3. Результаты и обсуждение}

Из результатов исследования поверхностной морфологии полученных образцов следует, что средняя высота НHК InP составляла 4 мкм, а диаметр оказался неоднородным по высоте и составил 100 нм у основания и 30 нм на вершине ННК при их поверхностной плотности $3 \cdot 10^{8} \mathrm{~cm}^{-2}$. На рис. 1, $a$ представлено ПЭМизображение участка ННК с нановставкой с размерами около 45 нм в длину, 10 нм в ширину и глубиной залегания в теле ННК меньше 10 нм. На рис. $1, b$ показано ПЭМ-изображение участка ННК с нанесенными коллоидными КТ. Как видно, КТ равномерно распределены по поверхности ННК без образования конгломератов. Расстояние между КТ и поверхностью ННК, а также между самими КТ составляет $\sim 1$ нм, что соответствует толщине лигандной оболочки КТ.

Для возникновения безызлучательного переноса энергии между донором (в нашем случае донорами являлись KT) и акцептором (InAsP-вставка) необходимо одновременное выполнение нескольких условий. В частности,

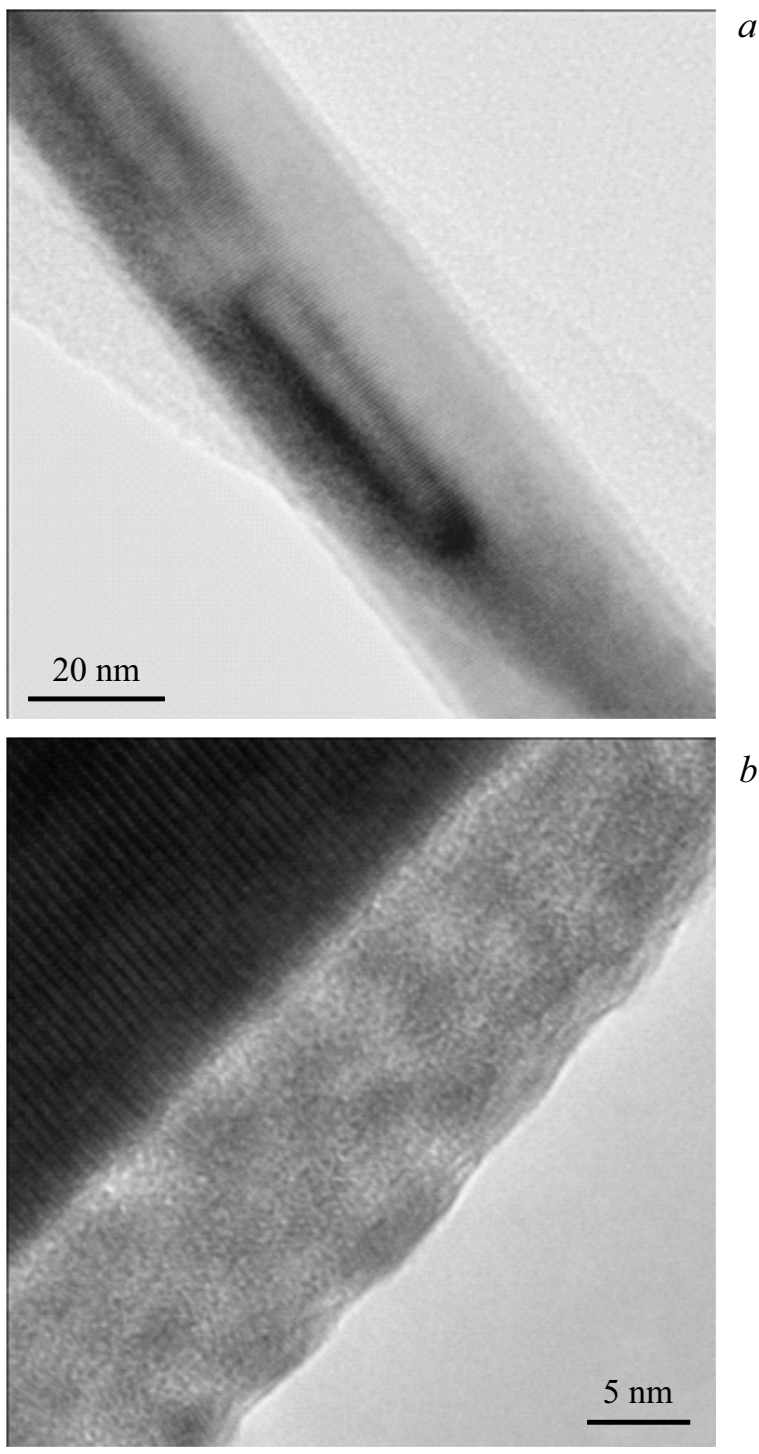

Рис. 1. ПЭМ-изображения высокого разрешения: $a-$ участок InAs НHK с нановставкой InAsP, $b-$ участок ННК после нанесения раствора с коллоидными $\mathrm{CdSe} / \mathrm{ZnS}$ KT.

спектр фотолюминесценции донора должен перекрываться со спектром поглощения акцептора, а расстояние между донором и акцептором должно быть $\sim 1-10$ нм. Оба этих основных критерия выполнялись для нашей гибридной структуры. В общем случае безызлучательный перенос энергии проявляется в снижении интенсивности и сокращении времени жизни ФЛ донора и одновременной обратной динамике этих параметров у акцептора.

Для подтверждения факта наличия переноса энергии были проведены спектрально-кинетические исследования ФЛ $\mathrm{CdSe} / \mathrm{ZnS}$ КТ и InAsP-вставки. В спектрах фотолюминесценции (ФЛ) массива ННК (при трех длинах волн возбуждения - 405, 532 и 633 нм) при комнатной температуре наряду с полосой, соответствующей межзонному излучению InP (0.93 мкм) (на рисунке не 
показана), наблюдался интенсивный сигнал ФЛ в области 1.25-1.5 мкм (рис. 2,a). Полоса ФЛ с максимумом в области 1.35 мкм соответствует излучению InAsPвставки. Менее интенсивная полоса в области 1.17 мкм, по-видимому, связана с радиальной квантовой ямой, образующейся при осаждении тонкого слоя InAsP на поверхность ННК во время роста вставки. На рис. $2, b$ приведены спектры ФЛ этого же образца с нанесенными коллоидными КТ. Как видно, полоса ФЛ от радиальной ямы (кроме случая возбуждения на длине волны 633 нм) практически полностью исчезла. При этом максимум ФЛ от нановставки сместился в длинноволновую область на $\sim 35$ нм.

Сравнение интенсивностей люминесценции гибридных наноструктур показало, что интенсивность ФЛ

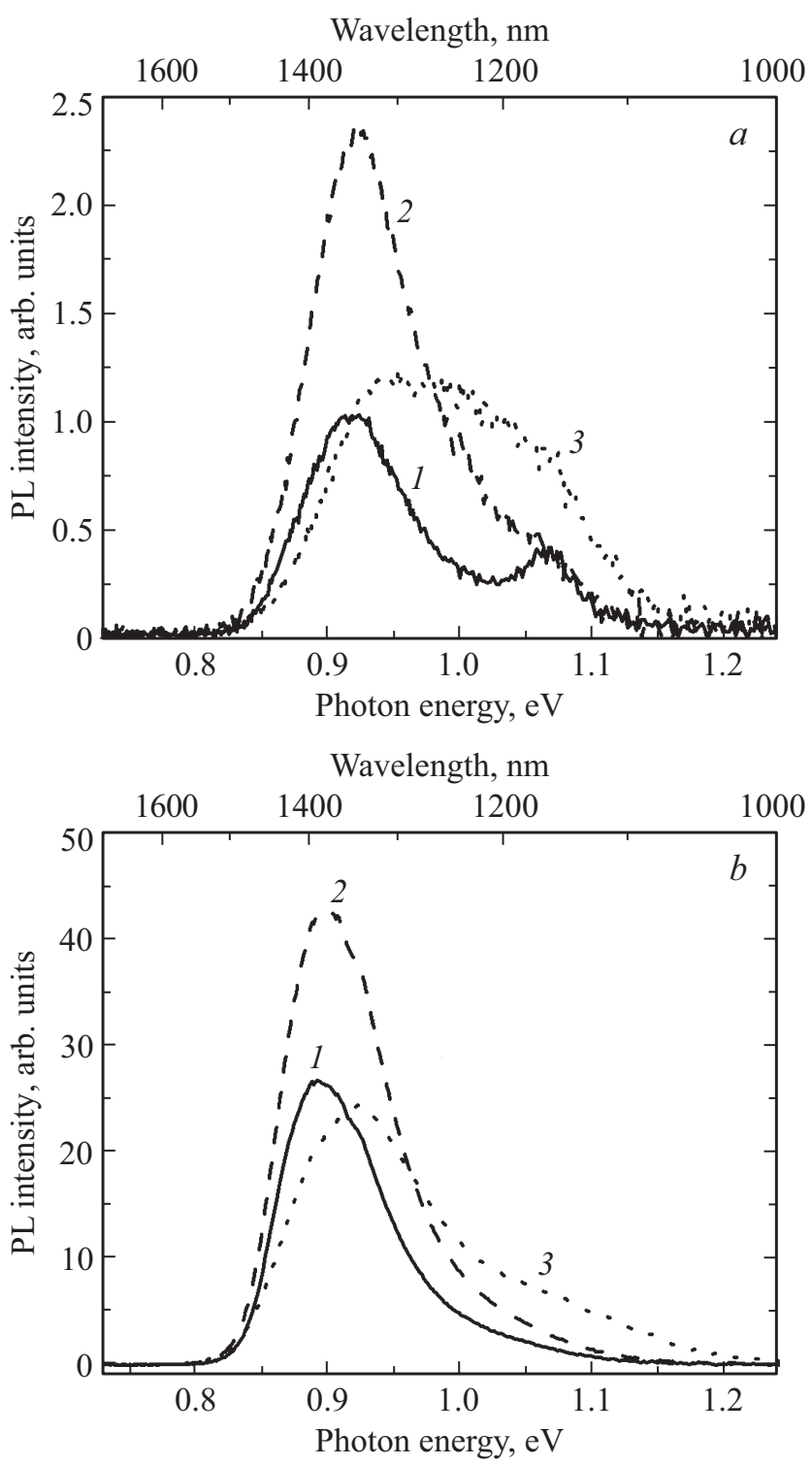

Pис. 2. Спектры ФЛ массива InP HНК с InAsP нановставкой: $a$ - до нанесения коллоидных CdSe/ZnS KT; $b-$ с нанесенными КТ. Цифрами обозначены спектры, полученные при разных длинах волн возбуждения: $1-405,2-532,3-633$ нм.

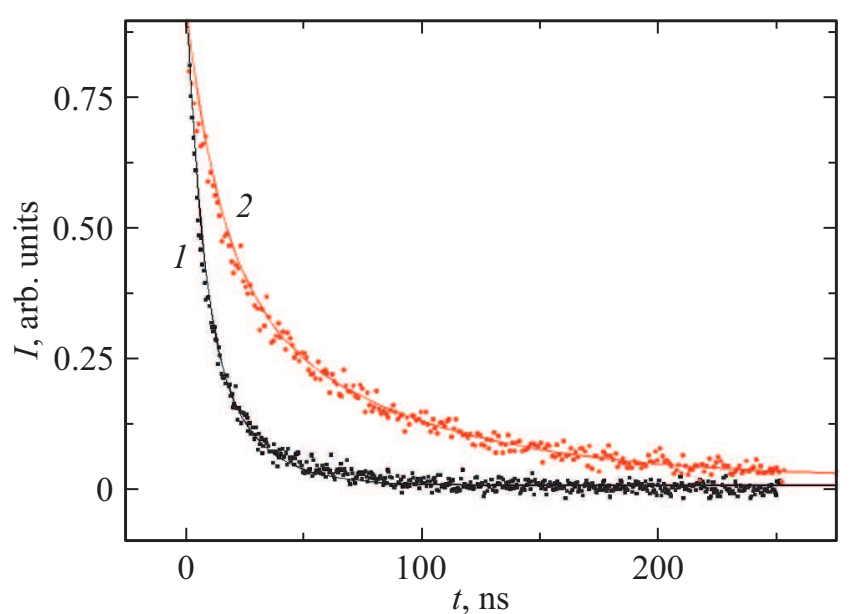

Рис. 3. Экспериментальная кинетика затухания люминесценции от вставки InAsP (1) и от вставки InAsP с нанесенными коллоидными КТ (2). Везде $\lambda_{\text {возб }}=633 \mathrm{HM}$.

InAsP-вставки в ННК с нанесенными коллоидными КТ по сравнению с образцом без нанесенных КТ возросла в среднем на порядок (измерения были проведены по нескольким точкам образцов), в то время как интенсивность ФЛ самих коллоидных КТ, наоборот, упала в 5-6 раз (при наличии вставки в ННК). Отметим, что форма и положение спектра люминесценции $\mathrm{CdSe} / \mathrm{ZnS}$ КТ не изменились при нанесении на ННК (спектры ФЛ КТ в растворе см., например, в работе [13]).

Исследования кинетики люминесценции проводились при возбуждении на длине волны 633 нм. При этом возбуждаются лишь самые большие по размеру квантовые точки, что исключает перенос энергии между самими КТ разного размера и упрощает общую картину исследования переноса энергии между КТ и нановставкой. В результате установлено, что среднее время жизни нанесенных коллоидных КТ при переходе от ННК без вставки к ННК со вставкой сократилось с 8.5 до 7 нс. В то время как среднее время жизни вставки InAsP увеличилось с 20 до 74 нс (рис. 3), что характерно, как говорилось выше, для случая безызлучательного переноса энергии.

Наиболее распространенным подходом к анализу кинетики затухания люминесценции квантовых точек при комнатной температуре является мультиэкспоненциальное разложение (см., например, [14]). В данной работе мы воспользовались двухэкспоненциальной функцией затухания. Из таблицы видно, что вклад обеих получен-

Времена жизни $\left(t_{i}\right)$ и соответствующие амплитуды $\left(A_{i}\right)$ люминесценции вставки InAsP

\begin{tabular}{l|c|c}
\hline Параметр & InAsP/InP & InAsP/InP + CdSe/ZnS \\
\hline$t_{1}$, нс & 25.3 & 85.9 \\
$A_{1}$, отн.ед. & 0.3 & 0.4 \\
$t_{2}$, нс & 5.3 & 13.1 \\
$A_{2}$, отн.ед. & 0.7 & 0.6
\end{tabular}


ных компонент в кинетику ФЛ нановставки InAsP практически одинаков, природу этих компонент предстоит установить в ходе дальнейших исследований.

Таким образом, полученные результаты свидетельствуют о безызлучательном переносе энергии (FRET) между составляющими наноструктуры, а именно между коллоидными КТ и квантово-размерной вставкой в ННК, в результате чего зарегистрировано более чем десятикратное увеличение интенсивности люминесценции с длиной волны излучения вблизи 1.3 мкм. Полученные результаты представляются исключительно интересными для задач связанных с созданием телекоммуникаций, использующих излучение ближнего ИК диапазона.

\section{Финансирование работы}

Работа выполнена при поддержке гранта РФФИ 18-02-40006 мега и гранта РНФ 19-72-30004.

\section{Конфликт интересов}

Авторы заявляют, что у них нет конфликта интересов.

\section{Список литературы}

[1] J. Briscoe, D.E. Gallardo, S. Hatch, V. Lesnyak, N. Gaponik, S. Dunn. J. Mater. Chem., 21, 2517 (2011).

[2] Meng-Lin Lu, Chih-Wei Lai, Hsing-Ju Pan, Chung-Tse Chen, Pi-Tai Chou, Yang-Fang. Nano Lett., 13, 1920 (2013).

[3] D. Hou, A. Dev, K. Frank, A. Rosenauer, T. Voss. J. Phys. Chem C, 116, 19604 (2012).

[4] А.И. Хребтов, В.Г. Талалаев, Р. Werner, В.В. Данилов, Б.В. Новиков, И.В. Штром, А.С. Панфутова, Г.Э. Цырлин. ФТП, 47 (10), 1356 (2013).

[5] А.И. Хребтов, В.Г. Талалаев, Ю.Б. Самсоненко, Р. Werner, В.В. Руцкая, М.В. Артемьев, Г.Э. Цырлин. Письма ЖТФ, 40 (13), 36 (2014).

[6] T. Förster. Ann. Phys., 437, 55 (1948).

[7] C.R. Kagan, C.B. Murray, M. Nirmal, M.G. Bawendi. Phys. Rev. Lett., 76, 1517 (1996).

[8] A.L. Rogach, T.A. Clar, J.M. Lupton, A. Meijerink, J. Feldmann. J. Mater. Chem., 19, 1208 (2009).

[9] D.M. Samosvat, O.P. Chikalova-Luzina, A.S. Stepashkina, G.G. Zegrya. Techn. Phys. Lett., 39, 74 (2013).

[10] P.L. Hernandez-Martinez, A.O. Govorov, H.V. Demiz. J. Phys. Chem. C, 118, 4951 (2014).

[11] Р.Р. Резник, Г.Э. Цырлин, И.В. Штром, А.И. Хребтов, И.П. Сошников, Н.В. Крыжановская, Э.И. Моисеев, А.Е. Жуков. Письма ЖТФ, 44 (3), 55 (2018).

[12] K.F. Chou, A.M. Dennis. Sensors, 15, 13288 (2015).

[13] В. В.Данилов, А.С. Панфутова, Г.М. Ермолаева, А.И. Хребтов, В.Б. Шилов. Опт. и спектр., 114 (6), 967 (2013).

[14] C. De Mello Donego, M. Bode, A. Meijerink. Phys. Rev. B, 74, 085320 (2006)

Редактор Г.А. Оганесян

\section{Nonradiative energy transfer in hybrid nanostructures with different dimensionalities}

\author{
A.I. Khrebtov ${ }^{1}$, R.R. Reznik ${ }^{2}$, E.V. Ubyivovk ${ }^{4}$, \\ A.P. Litvin' ${ }^{2}$, I.D. Skurlov' ${ }^{2}$, P.S. Parfenov' ${ }^{2}$, \\ A.S. Kulagina ${ }^{1}$, V.V. Danilov ${ }^{3}$, G.E. Cirlin ${ }^{1,2,5,6}$ \\ ${ }^{1}$ St. Petersburg Academic University - \\ Nanotechnology Research and Education Centre \\ Russian Academy of Sciences, \\ 194021 St. Petersburg, Russia \\ ${ }^{2}$ St. Petersburg National Research University of \\ Information Technologies, Mechanics and Optics, \\ 197101 St. Petersburg, Russia \\ ${ }^{3}$ St. Petersburg State Transport University, \\ 191031 St. Petersburg, Russia \\ ${ }^{4}$ Fock Institute of Physics, \\ St. Petersburg State University, \\ 198504 Petrodvorets, Russia \\ ${ }^{5}$ Institute for Analytical Instrumentation, \\ Russian Academy of Sciences, \\ 190103 St. Petersburg, Russia \\ ${ }^{6}$ St. Petersburg Electrotechnical University „LETI“, \\ 197376 St. Petersburg, Russia
}

\begin{abstract}
We have demonstrated the possibility to create a composite system based on InP nanowires with InAsP nanoinsertion grown on the $\mathrm{Si}(111)$ substrate by the molecular beam epitaxy, and $\mathrm{CdSe} / \mathrm{ZnS}$ colloidal quantum dots. Nonradiative resonance energy transfer between colloidal quantum dots and nanoinsertions was experimentally observed.
\end{abstract}

